\title{
Урожайность различных сортов картофеля и их повреждение вредителями в условиях Удмуртской Республики
}

\author{
Yields of different potato cultivars and their damage by insect pests in the Udmurt Republic
}

\author{
Эсенкулова О.В., Коробейникова О.В., Маслова М.П.
}

\section{Аннотация}

В рамках развития органического сельского хозяйства актуально выявление сортов с высокой устойчивостью к вредным организмам. В условиях Удмуртской Республики на дерново-среднеподзолистой среднесуглинистой слабосмытой почве в 2017-2018 годах проводились исследования, целью которых была оценка новых и перспективных сортов картофеля различных по срокам созревания. Одной из задач было выявление повреждений клубней вредителями. Изучали сорта картофеля разных сроков созревания: раннеспелые - Нандина, Ред Соня, Колетте, Беллароза, Винета, Джоконда, Раноми; среднеспелые - Джелли, Вираж, Гала, Рябинушка, Каптива, Алуэт; позднеспелые - Ред Фентази, Церата КВС, Танго. Полевой однофакторный опыт закладывался согласно методике полевого опыта. Клубневой анализ проводили в соответствии с ГОСТ 33996-2016 Картофель семенной. Технические условия и методы определения качества. Коэффициент адаптивности изучаемых сортов картофеля рассчитан по методу Л.А. Животкова. За два года исследований более урожайными были раннеспелые сорта: Нандина, Ред Соня, Беллароза, Раноми; среднеспелые: Джелли, Каптива, Алуэт; позднеспелые: Ред Фентази и Церата КВС. Повреждение клубней картофеля личинками щелкуна (проволочником) было очень высоким и составило в 2017 году в среднем по сортам 47\%, в 2018 году - 61\%. В оба года исследований клубни были повреждены личинками озимой совки (в среднем 3-4 \%), личинками майского хруща (1-2 \%). В 2018 году наблюдалось повреждение полевками (в среднем по сортам 3 \%). Раннеспелые сорта являются более адаптивными к условиям Удмуртской Республики (коэффициент адаптивности 1,22 и 1,31). Однако качество посадочного материала не соответствует ГОСТ по проценту повреждений вредителями. Поэтому необходима тщательная сортировка и доведение клубней до регламентируемых показателей. Для снижения поврежденности в полевых условиях картофель требуется размещать после бобовых и крестоцветных культур, проводить известкование почв и вносить перепревшие органические удобрения.

Ключевые слова: картофель, сорта, группы спелости, повреждение клубней картофеля вредителями, биологическая урожайность, коэффициент адаптивности.

Для цитирования: Эсенкулова О.В., Коробейникова О.В., Маслова М.П. Урожайность различных сортов картофеля и их повреждение вредителями в условиях Удмуртской Республики // Картофель и овощи. 2020. №1. С. 28-31. https://doi.org/10.25630/ PAV.2020.24.84.002

\author{
Esenkulova O.V., Korobeinikova O.V., Maslova M.P.
}

\section{Abstract}

As part of the development of organic agriculture, the identification of varieties with high resistance to pests is relevant. In the conditions of the Udmurt Republic, studies were carried out in 2017-2018 on the derno-medium-soil average carbon-free weak soil, the purpose of which was to assess new and permissive potato cultivars of different maturation times. One challenge was to identify damage to tubers by insect pests and the possibility of using them as planting material. Potato cultivars of different maturation dates were studied: early - Nandina, Red Sonya, Kolette, Bellaroza, Vineta, Dzhokonda, Ranomi; medium - Dzhelli, Virazh, Gala, Ryabinushka, Kaptiva, Aluet; late - Red Fentazi, Tserata KVS, Tango. Field onefactor experiment was laid according to the method of experimental work. Tuberous analysis was carried out in accordance with GOST 33996-2016 «Seed Potatoes. Technical conditions and methods of quality determination». The coefficient of adaptivity of the studied potato cultivars is calculated according to the method of L.A. Zhemkov. More crop-producing were early cultivars: Nandina, Red Sonya, Bellaroza, Ranomi; average: Dzhelli, Kaptiva, Aluet; late: Red Fentazi and Tserata CF. During the years of research, there was damage to potato tubers by wireworm in 2017 on average 47\%, and in $2018-61 \%$. The only cultivar, Ranomi, was not damaged by the wireworm in 2017. A small number of tubers was damaged by larvae of turnip moth (Agrotis segetum) (3-4\%) and larvae of white grub $(1-2 \%)$. During two years of research in the Udmurt Republic early cultivars were more adaptive, the coefficient of adaptability was 1,31 and 1,22. However, the quality of the planting material by the percentage of damaged tubers by pests does not comply with state standard. For growing in the region, early cultivars Nandin, Red Sonya, Kolette, Bellarosa, Vineta, Dzhokonda, Ranomi are more suitable; from middle cultivars Dzhelli, Kaptiva and Aluet turned out to be more stable; from late ripening - Red Fentazi. Due to severe damage by insect pests, especially wireworms, careful sorting and bringing tubers to regulated parameters, liming of soils, and introduction of rotted organic fertilizers are necessary, as well as to place potatoes in crop rotation after legumes and cruciferous crops.

Key words: potato, cultivars, groups of ripeness, damage to potato tubers by insect pests, biological yield, coefficient of adaptability.

For citing: Esenkulova O.V., Korobeinikova O.V., Maslova M.P. Yields of different potato cultivars and their damage by insect pests in the Udmurt Republic. Potato and Vegetables. 2020. No1. Pp. 28-31 (In Russ.). https://doi.org/10.25630/PAV.2020.24.84.002 артофель - одна из востребованных и широко распространенных с. - х. культур не только на территории России, но и в мире. В связи с широким ареалом возделывания и различными направлениями использования требуется создание большого количества новых приспособленных к конкретным почвенно-климатическим условиям сортов $[1,2,3]$. Удмуртская Республика входит в число регионов Нечерноземной зоны, расположенных в зоне рискованного земледелия. Выращиванием картофеля занимаются многие хозяйства республики. Площадь возделывания за последние шесть лет составила от 25,0 тыс. до 31,8 тыс. га (2,5-3,4\% от общей площади с.- x. культур). Валовой сбор за этот же период составил 393 тыс.- 408 тыс. т, с урожайностью 12,8-18,6 т/га [4].

Важнейший фактор роста урожайности - современные высокотех- нологичные сорта и семеноводство. В Удмуртском НИИСХ - структурном подразделении Удмуртского ФИЦ УрО РАН производят семенной материал картофеля на безвирусной основе.

Уровень урожайности картофеля и качество клубней зависят преимущественно от распространенности и развития вредных организмов. По данным ВНИИКХ ежегодный недобор урожая картофеля от болезней и вредителей, составляет 23-29\%, а в некоторые годы 
превышает 50\% [5, 6]. Спрос на экологически чистую продукцию устойчиво растет. В январе 2020 года в России вступает в силу Федеральный закон от 03.08.2018г. № 280 «Об органической продукции...», в котором одно из требований - это запрет применения агрохимикатов и пестицидов. Удмуртская Республика также включается в данное направление развития сельского хозяйства и в связи с этим актуальным является выявление сортов с высокой устойчивостью к вредным организмам.

Цель исследований - оценка новых и перспективных сортов различных по срокам созревания, адаптированным для выращивания в условиях Удмуртской Республики. Одна из задач - выявление повреждений клубней вредителями и возможность их использования в качестве посадочного материала.

Условия, материалы и методы исследований

Исследования проводили в 2017 2018 годах на опытном поле ФГБОУ ВО Ижевская ГСХА. Почва опытного участка - дерново-среднеподзо- листая среднесуглинистая слабосмытая. Реакция почвенной среды - среднекислая $\left(\mathrm{pH}_{\mathrm{KCl}} 4,70-\right.$ 4,87), содержание гумуса - среднеe $(2,42-2,50 \%)$, степень насыщенности основаниями - высокая (9295\%), содержание подвижного фосфора и обменного калия - высокое (237-246 мг/Кг).

Закладка опыта - согласно методике опытного дела [7]. Предшественник - яровые зерновые культуры. Способ посадки широкорядный, норма посадки - 60 тыс. клубней на 1 га (6 шт/М²). В схему полевого однофакторного опыта были включены сорта картофеля разных сроков созревания: раннес-

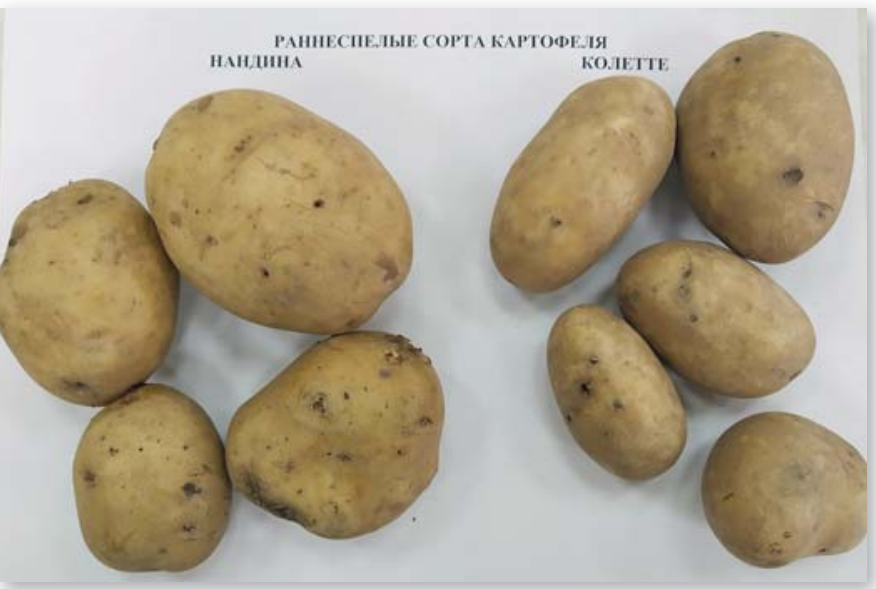

Рис. 1. Повреждение проволочником раннеспелых сортов Нандина и Колетте

пелые - Нандина, Ред Соня, Колетте, Беллароза, Винета, Джоконда, Раноми; среднеспелые -Джелли, Вираж, Гала, Рябинушка, Каптива, Алуэт; позднеспелые - Ред Фентази, Церата КВС, Танго.

Среди изучаемых сортов в Государственный реестр селек-

Таблица 1. Биологическая урожайность различных сортов картофеля и повреждение клубней вредителями, 2018-2019 годы

\begin{tabular}{|c|c|c|c|c|c|c|c|c|c|c|c|}
\hline \multirow{3}{*}{ Сорт } & \multirow{2}{*}{\multicolumn{5}{|c|}{$\begin{array}{l}\text { Повреждение клубней, \% } \\
2017\end{array}$}} & \multicolumn{2}{|c|}{ Урожайность, кг/м² } & \multicolumn{4}{|c|}{ Повреждение клубней, \% } \\
\hline & & & & & & \multicolumn{6}{|c|}{2018} \\
\hline & всего & $\begin{array}{l}\text { откл. от } \\
\text { ср. }\end{array}$ & $\begin{array}{l}\text { прово- } \\
\text { лочник }\end{array}$ & $\begin{array}{l}\text { озимая } \\
\text { совка }\end{array}$ & $\begin{array}{c}\text { майский } \\
\text { хрущ }\end{array}$ & всего & $\begin{array}{l}\text { откл. от } \\
\text { ср. }\end{array}$ & $\begin{array}{l}\text { прово- } \\
\text { лочник }\end{array}$ & $\begin{array}{l}\text { озимая } \\
\text { совка }\end{array}$ & $\begin{array}{c}\text { майский } \\
\text { хрущ }\end{array}$ & грызуны \\
\hline 1. Нандина & 1,35 & 0,02 & 80 & 16 & 6 & 8,02 & 3,48 & 78 & 0 & 0 & 10 \\
\hline 2. Ред Соня & 1,71 & 0,34 & 13 & 0 & 0 & 6,32 & 1,78 & 96 & 0 & 2 & 4 \\
\hline 3. Колетте & 1,16 & $-0,21$ & 70 & 2 & 4 & 4,31 & $-0,23$ & 100 & 2 & 2 & 0 \\
\hline 4. Беллароза & 2,40 & 1,03 & 45 & 0 & 5 & 4,49 & $-0,05$ & 85 & 0 & 0 & 6 \\
\hline 5. Винета & 0,95 & $-0,42$ & 10 & 15 & 0 & 4,40 & $-0,14$ & 91 & 0 & 3 & 3 \\
\hline 6. Джоконда & 1,84 & 0,47 & 22 & 2 & 0 & 3,70 & $-0,84$ & 56 & 0 & 6 & 0 \\
\hline 7. Раноми & 1,14 & $-0,23$ & 0 & 0 & 0 & 6,75 & 2,21 & 74 & 12 & 4 & 2 \\
\hline $\begin{array}{l}\text { Среднее по ран- } \\
\text { неспелым сортам }\end{array}$ & 1,51 & 0,14 & 34 & 5 & 2 & 5,43 & 0,89 & 83 & 2 & 2 & 4 \\
\hline 8. Джелли & 1,18 & $-0,19$ & 82 & 0 & 0 & 4,83 & 0,29 & 68 & 24 & 8 & 6 \\
\hline 9. Вираж & 1,50 & 0,13 & 24 & 0 & 0 & 2,87 & $-1,67$ & 22 & 0 & 0 & 4 \\
\hline 10. Гала & 0,98 & $-0,39$ & 92 & 0 & 0 & 3,28 & $-1,26$ & 74 & 0 & 0 & 2 \\
\hline 11. Рябинушка & 1,00 & $-0,37$ & 62 & 0 & 0 & 2,29 & $-2,25$ & 20 & 0 & 0 & 0 \\
\hline 12. Каптива & 1,75 & 0,38 & 46 & 6 & 0 & 4,39 & $-0,15$ & 60 & 0 & 0 & 12 \\
\hline 13. Алуэт & 1,06 & $-0,31$ & 58 & 0 & 0 & 4,52 & $-0,02$ & 12 & 0 & 0 & 0 \\
\hline $\begin{array}{l}\text { Среднее по средне- } \\
\text { спелым сортам }\end{array}$ & 1,28 & $-0,09$ & 57 & 2 & 0 & 3,94 & $-0,60$ & 48 & 4 & 1 & 4 \\
\hline $\begin{array}{l}\text { 14. Ред } \\
\text { Фентази }\end{array}$ & 2,12 & 0,75 & 28 & 0 & 0 & 4,58 & 0,04 & 22 & 10 & 0 & 0 \\
\hline 15. Церата КВС & 0,72 & $-0,65$ & 70 & 12 & 0 & 4,55 & 0,01 & 64 & 0 & 4 & 0 \\
\hline 16. Танго & 1,07 & $-0,30$ & 53 & 8 & 0 & 3,27 & $-1,27$ & 54 & 0 & 0 & 6 \\
\hline $\begin{array}{l}\text { Среднее по позднес- } \\
\text { пелым сортам }\end{array}$ & 1,30 & 0,07 & 50 & 7 & 0 & 4,13 & $-0,41$ & 47 & 3 & 1 & 2 \\
\hline Среднее по сортам & 1,37 & - & 47 & 4 & 1 & 4,54 & - & 61 & 3 & 2 & 3 \\
\hline $\mathrm{HCP}_{05}$ & - & 0,77 & - & - & - & - & 1,40 & & & & \\
\hline
\end{tabular}




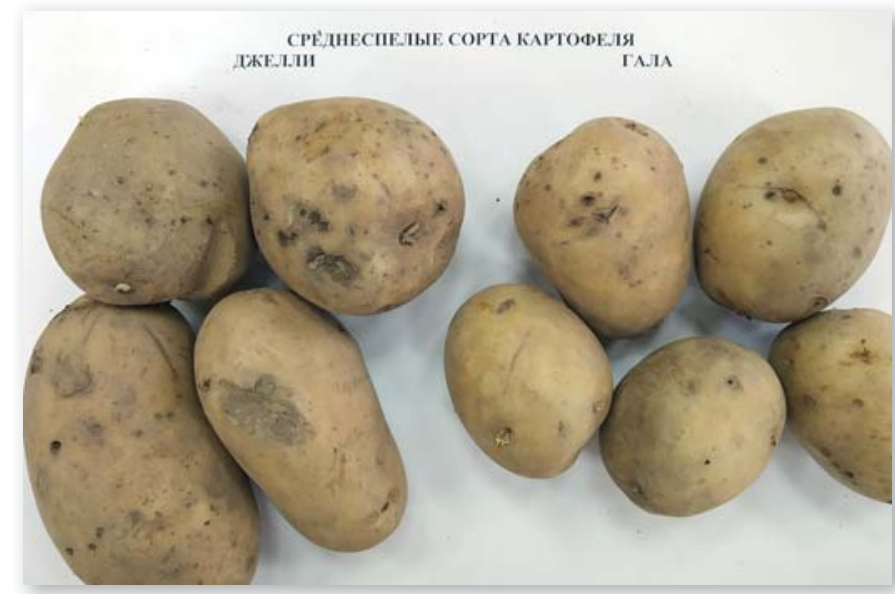

Рис. 2. Повреждение проволочником среднеспелых сортов Джелли и Гала

\section{в программе Excel.}

вой анализ в соответствии с ГОСТ $33996-2016$ Картофель семенной. Технические условия и методы определения качества [10]. Результаты эксперимента подвергали дисперсионному анализу по алгоритмам, разработанным Б.А. Доспеховым. Обработку результатов исследований проводили на ПК в среде Microsoft Office

ПОЗДНЕСПЕЛЫЙ СОРТ КАРТОФЕЛЯ ДЕРАТА KBC

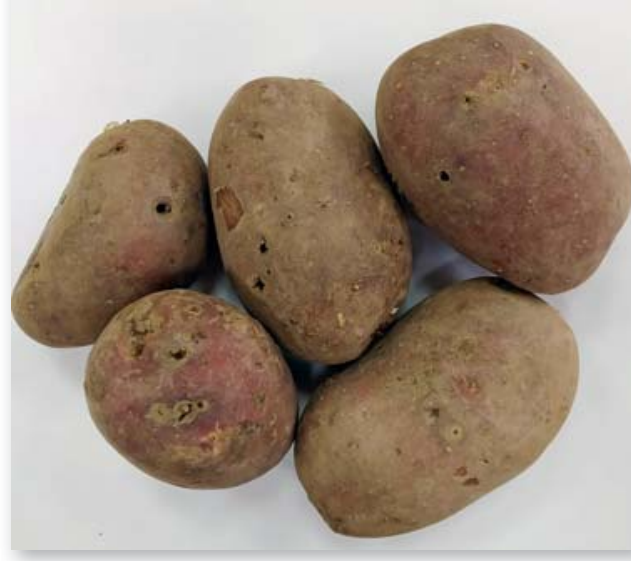

Рис. 3. Повреждение проволочником позднеспелого сорта Церата КВС

ционных достижений по ВолгоВятскому (4) региону включены 11 сортов (Нандина, Ред Соня, Колетте, Беллароза, Винета, Джелли, Рябинушка, Гала, Ред Фентази, Вираж, Алуэт). Сорта Джоконда, Раноми, Каптива, Церата КВС включены в Госреестр по другим регионам [8]. Сорт Танго находится на Государственном сортоиспытании.

Уход за растениями картофеля с применением общепринятых агротехнических приемов. Защиту растений от вредителей и болезней не проводили, с целью выявления потенциальной устойчивости сортов. Учет болезней проводился визуально методом проб [9]. Уборка урожая - вручную с поделяночным взвешиванием продукции по каждой калибровочной фракции. Через месяц после уборки был проведен клубне-
Метеорологические условия в годы исследований были различны и оказали существенное влияние на урожайность картофеля. Вегетационный период 2017 года характеризовался как холодный и дождливый. Такие условия способствовали массовому поражению растений болезнями. В результате растения картофеля уже в начале августа были поражены фитофторозом. Вегетация растений была растянута, не хватало тепла, поэтому поздние сорта картофеля не успели вызреть. В 2018 году начало лета (июнь) было холодным. Затем температура воздуха резко повысилась и установилась на уровне несколько выше среднемноголетних показателей. Из двух лет исследований 2018 год оказался более благоприятным для картофеля (табл. 1).

\section{Результаты исследований}

Сравнительно высокая урожайность для погодных условий 2017 года получена у сорта Беллароза (2,40 кг/м²). Урожайность остальных сортов находилась в пределах от 0,72 до 2,12 кг/м².

В более благоприятный для картофеля 2018 год урожайность большинства сортов варьировала от 3,27 до 4,83 кг/м². Меньшая урожайность была отмечена у сортов Вираж

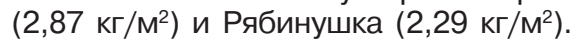
Высокая урожайность получена у сортов Нандина, Раноми и Ред Соня $(8,02$; 6,75 и 6,32 кг/м² соответственно).

У клубней картофеля, предназначенных на семенные цели, нормируется повреждение клубней вредителями. Согласно ГОСТ 33996-2016 в семенном материале допускаются клубни, с повреждениями проволочником, грызунами, хрущами и совками, но без повреждения глазков в совокупности не более $2 \%$.

В оба года исследований отмечено интенсивное повреждение клубней картофеля личинками щелкуна (проволочником) (семейство Elateridae). В дождливое лето 2017 года проволочники питались в верхнем слое почвы, поэтому отмечено большое количество поврежденных клубней (в среднем по сортам 47\%). Единственный сорт, на котором не отмечено повреждение проволочником - это Раноми. Кроме проволочника 4\% клубней в 2017 году были повреждены личинками озимой совки (Scotia (Agrotis) segetum Schiff.) и майского хруща (Melolontha melolontha Linnaeus). Не были повреждены данными вредителями раннеспелые сорта Ред

\section{Таблица 2. Коэффициент адаптивности сортов картофеля}

\begin{tabular}{|c|c|c|c|c|c|}
\hline \multirow[t]{2}{*}{ Сорт } & \multicolumn{2}{|c|}{$\begin{array}{c}\text { Коэффициент } \\
\text { адаптивности } \\
\text { по годам }\end{array}$} & \multirow[t]{2}{*}{ Сорт } & \multicolumn{2}{|c|}{$\begin{array}{c}\text { Коэффициент } \\
\text { адаптивности } \\
\text { по годам }\end{array}$} \\
\hline & 2017 & 2018 & & 2017 & 2018 \\
\hline 1. Нандина & 1,28 & 1,81 & 10. Гала & 0,88 & 0,74 \\
\hline 2. Ред Соня & 1,51 & 1,43 & 11. Рябинушка & 1,51 & 0,52 \\
\hline 3. Колетте & 1,02 & 0,97 & 12. Каптива & 1,04 & 0,99 \\
\hline 4. Беллароза & 1,96 & 1,01 & 13. Алуэт & 0,82 & 1,02 \\
\hline 5. Винета & 0,79 & 0,99 & $\begin{array}{l}\text { Среднее } \\
\text { по среднеспелым сортам }\end{array}$ & 1,09 & 0,84 \\
\hline 6. Джоконда & 1,71 & 0,84 & 14. Ред Фентази & 1,80 & 1,03 \\
\hline 7. Раноми & 0,87 & 1,52 & 15. Церата КВС & 0,59 & 1,03 \\
\hline $\begin{array}{l}\text { Среднее } \\
\text { по раннеспелым сортам }\end{array}$ & 1,31 & 1,22 & 16. Танго & 0,96 & 0,74 \\
\hline 8. Джелли & 1,05 & 1,09 & $\begin{array}{l}\text { Среднее } \\
\text { по позднеспелым сортам }\end{array}$ & 1,12 & 0,93 \\
\hline 9. Вираж & 1,26 & 0,65 & & & \\
\hline
\end{tabular}


Соня и Раноми, все среднеспелые (кроме Каптивы), позднеспелый Ред Фентази. в 2018 год была более высокой, чем в предыдущий год и составила $61 \%$. Интенсивно повреждались раннеспелые сорта (83\%). Кроме того, в этот год клубнями картофеля питались полевки (род Microtus) (в среднем по сортам

Для получения информации о приспособленности сортов рассчитали коэффициент адаптивности по методу Л. А. Животкова $[11,12]$ (табл. 2).

Установлено, что хорошей адаптивностью обладали большинство раннеспелых сортов; из группы сред-
Повреждение клубней картофеля повреждение составило 3\%). неспелых - Джелли, Вираж, Каптива и Алуэт; из группы позднеспелых Ред Фентази и Церата КВС. В целом по сортам, за два года исследований выявлено, что более адаптивна к условиям Удмуртской Республики группа раннеспелых сортов (коэффициент адаптивности 1,22-1,31).

\section{Выводы}

Таким образом, в условиях Удмуртской Республики для возделывания более подходят раннеспелые сорта картофеля. Из среднеспелых более стабильными оказались сорта Джелли, Каптива и Алуэт. Из позднеспелых - Ред Фентази. Однако в оба года исследований изучаемые сорта были сильно повреждены вредителями, особенно про-

\section{Библиографический список}

1.Митрюкова Ю.В. Сорт - средство получения высокого урожая картофеля // Устойчивому развитию АПК - научное обеспечение. Материалы республиканской науч.-практ. конФ. ФГБОУ ВПО «Ижевская ГСХА» Т. 1. Ижевск: РИО ФГОУ ВПО ИжГСХА, 2004. С. 109-112.

2.Баталова Г.А., Стариков В.А. Картофель: производство, сорта и семеноводство // Аграрная наука Евро-Северо-Востока. 2009. № 3 (14). С. 4-8.

3.Оценка сортов картофеля разных сроков созревания / О.В. Коробейникова, Т.А. Строт, М.П. Маслова, О.В. Эсенкулова // Вестник Ижевской государственной сельскохозяйственной академии. 2018. № 2 (55). С. 36-47.

4.Валовые сборы и урожайность сельскохозяйственных кульбюллетень. Ижевск, 2019. 154 с.

5.Влияние схем обработок на пораженность картофеля болезнями // М.К. Деревягина, С.В. Васильева, Г.Л. Белов [и др.] // Защита картофеля. 2017. № 2. С. 28-32.

6.Сорт - главное звено адаптивной технологии возделывания картофеля // В.Н. Зейрук, М.К. Деревягина С.В. Васильева, В.М. Глез // Защита картофеля. 2014. № 1. С. 8-9.

7.Доспехов Б.А. Методика полевого опыта. М.: Агропромиздат, 1985. $351 \mathrm{c}$.

8.Государственный реестр селекционных достижений. Сорта полевых культур. ФГУ «Госсорткомиссия». Москва, 2017. 483 с.

9. Фитосанитарная диагностика / А.Ф. Ченкин, В.А. Захаренко, Г.С. Белозерова [и др.]; Под ред. А.Ф. Ченкина. М.: Колос, 1994. $323 \mathrm{c}$.

10.ГОСТ 33996-2016 Картофель семенной. Технические условия и методы определения качества [Электронный ресурс]. URL: http://docs.cntd.ru/document/1200143601. Дата обращения: 19.12.2019.

11.Животков Л.А., Морозова З.А., Секутаева Л.И. Методика выявления потенциальной продуктивности и адаптивности сортов и селекционных форм озимой пшеницы по показателю урожайности // Селекция и семеноводство. 1994. № 2. С. 3-5.

12.Макаров В.И., Хлопюк М.С. Оценка сортов картофеля // Картофель и овощи. 2017. №8. С. 31-33. тур по Удмуртской Республике в 2018 году / Статистический

волочником, что характерно для всей территории Удмуртской Республики. Поэтому, для использования клубней в качестве семенного материала необходима тщательная сортировка и доведение клубней до регламентируемых нормативов. Для снижения поврежденности клубней картофель необходимо размещать после бобовых и крестоцветных культур (менее повреждаемых проволочником), исключить возделывание картофеля после многолетних злаковых трав и на запыреенных участках. Для восполнения питательных веществ и снижения популяции щелкунов проводить известкование кислых почв и внесение перепревших органических удобрений.

\section{References}

1.Mitryukova Yu.V. Cultivar is a means of obtaining a high yield of potatoes. Sustainable development for the agricultural sectorscientific support. Materials of the Republican Scientific and Practical Conference, Izhevsk State Agricultural Academy Vol. 1. Izhevsk. Izhevsk State Agricultural Academy. 2004. Pp. 109-112 (In Russ.).

2.Batalova G.A., Starikov V.A. Potatoes: production, varieties and seed production. Agrarian science of Euro-North-East. 2009. №. 3 (14). Pp. 4-8 (In Russ.).

3.Korobeynikova O.V., Strot T.A., Maslova M.P., Esenkulova O.V. Assessment of potato cultivars of different ripening groups. Bulletin of Izhevsk State Agricultural Academy. 2018. No 2 (55). Pp. 36-47 (In Russ.).

4.Gross fees and crop yields in the Udmurt Republic in 2018. Statistical Bulletin. Izhevsk, 2019. 154 p. (In Russ.).

5.Derevyagina M.K., Vasil'eva S.V., Belov G.L. [et al.]. Influence of treatment schemes on disease affecting potato. Potato protection. 2017. No 2. Pp. 28-32 (In Russ).

6.Zeyruk V.N., Derevyagina M.K., Vasil'eva S.V., Glez V.M. Cultivar is the main link of adaptive potato growing technology. Potato protection. 2014. No1. Pp. 8-9 (In Russ).

7.Dospekhov B.A. Methodology of field experiment. Moscow. Agropromizdat. 1985. $351 \mathrm{p} \mathrm{(In} \mathrm{Russ.).}$

8.State Register of Breeding Achievements. Varieties of field crops. Federal state institution «State Commission». Moscow. 2017. $483 p$ (In Russ.).

9.Phytosanitary diagnostics / A. F. Chenkin, V. A. Zaharenko, G. S. Belozerova [et al.]; Ed. A. F. Chenkina. M. : Kolos, 1994. 323 p (In Russ.).

10.GOST 33996-2016 Seed potatoes. Technical conditions and methods of quality determination. URL: http://docs.cntd.ru/ document/1200143601 (In Russ.). Access date: 19.12.1019.

11.Zhivotkov L. A. Method of identification of potential productivity and adaptability of varieties and breeding forms of winter wheat in terms of yield. L. A. Zhivotkov, Z. A. Morozova, L. I. Sekutaeva // Breeding and seed production. 1994. № 2. Pp. 3-5 (In Russ.).

12. Makarov V. I. evaluation of potato varieties. V. I. Makarov, M. S. Hlopjuk. Potatoes and vegetables. 2017. № 8. Pp. 31-33 (In Russ.).

\section{Об авторах}

Эсенкулова Ольга Владимировна, канд. с.-х. наук, доцент кафедры земледелия и землеустройства, ФГБОУ ВО Ижевская ГСХА. Тел.: +7 (950) 178-50-47. E-mail: o.w.esen@mail.ru

Коробейникова Ольга Валентиновна, канд. с.-х. наук, доцент кафедры земледелия и землеустройства, ФГБОУ ВО Ижевская ГСХА. Тел. +7 (951) 216-23-78. E-mail: korobejnikova.olga@inbox.ru

Маслова Мария Павловна, кандидат с.-х. наук, доцент кафедры земледелия и землеустройства, ФГБОУ ВО Ижевская ГСХА. Тел.+7(950)162-03-74. E-mail: mary.maslova2009@yandex.ru

\section{Author details}

Esenkulova O.V., Cand. Sci. (Agr.), associate professor, department of agricultural and land management, Izhevsk State Agricultural Academy. Phone: +7(950) 1785047. E-mail: o.w.esen@mail.ru

Korobeinikova O.V., Cand. Sci. (Agr.), associate professor, department of agricultural and land management, Izhevsk State Agricultural Academy. Phone:+7(951)2162378. E-mail: korobejnikova.olga@inbox.ru

Maslova M.P., Cand. Sci. (Agr.), associate professor, department of agricultural and land management, Izhevsk State Agricultural Academy. Phone:+7(950)162-03-74. E-mail: mary.maslova2009@yandex.ru 